\title{
Twinning Rates in Ghana
}

\author{
A.A. Mosuro*,A.N.Agyapong, M. Opoku-Fofie and S. Deen. \\ Department of Zoology, University of Ghana, Legon, Accra, Ghana
}

\begin{abstract}
The incidence of twin births in Accra and Kumasi, the two major cities in Ghana, was investigated. In Accra, data were collected from the Korle-Bu Teaching Hospital while data were collected and analyzed from the Komfo Anokye Teaching Hospital in Kumasi. Both hospitals are the leading teaching hospitals in Ghana. The data consisted mainly of single and twin births recorded in the hospitals over a period of 12 years in Accra (1988-1999) and 15 years in Kumasi (1985-1999). The study revealed an incidence of 33.4 twin births per thousand live births for Accra and 26.6 twin births per thousand live births for Kumasi. Though these values are not as high as those reported among the Yoruba tribe of southwest Nigeria, who are reported to have the highest twin birth rates in the world, the present values still rank among the highest recorded twin birth rates.
\end{abstract}

Most demographic studies include birth rates, death rates, secondary sex ratios, age distribution patterns and many other parameters. Of equal importance, not only to demographers but also to population geneticists, is the incidence of twinning among the different populations of the world, which is believed by many to differ by geographic location and also by race. The highest rate of natural twinning occurs among the Yoruba tribe in Nigeria, and the lowest rate occurs in Asian women, (Bulmer, 1970; Keith \& Keith, 1999). Twin and other multiple births have always aroused a keen interest in all cultures.

Twinning is an extensively studied phenomenon with reports dating as far back as the 19th century. Twinning has been reported to be influenced by a number of biological and non-biological factors. One major biological factor is maternal age. Nylander (1981) reported that the age group in which the highest number of twin births occurred seemed to be fairly constant at 30-40 years. Parity or the number of children previously borne has also been reported to influence twinning (Bulmer,1970; MacGillivray,1981). Genetic factors have also been implicated. Bulmer (1970), and Goswami (1970) both reported the influence of heredity on twinning and it is now widely believed that the hormonal levels that stimulate natural ovulation also differ between the races and that twinning clearly appears to run in specific families. Mosuro (1996) reported that the very high twinning rates observed in Igbo-Ora, a rural Yoruba settlement in southwest Nigeria, could have been due to the fact that the people are homogeneous culturally, socially, ethnically and may even be consanguineous, encouraging marriage between close relatives, and that if the population was indeed genetically predisposed to twinning, one should then expect the twinning rates to be naturally high. Campbell et al. (1974) and Nylander
(1981) reported that maternal height may also be a determining factor.

There has been little agreement as to whether twin births show seasonal variation and especially about whether there is any universal pattern. One plausible explanation for this may be that different populations have been studied for different periods of time and that the factors, geophysical and socio-economic, that may influence the seasonal variation of twinning, vary in different populations. Furthermore, the statistics for twin maternities depend on different demographic principles and genetic factors, such as maternal age and parity distributions of the mothers and the population-specific twinning rates. These are known to vary greatly between populations and over time. Nylander (1981), Fellman and Eriksson (1999) and Keith and Keith (1999) all reported extensively on the influence of seasonal variation on twinning rates.

Non-genetic factors such as social class have also been reported to influence twinning (Nylander, 1981).

Yet another factor implicated are fertility drugs. Edgley (1969) reported that the use of fertility drugs in the treatment of anovulation, amenorrhoea and sterility, is known to stimulate ovary development and ovulation and can eventually lead to the hyperstimulation of the ovaries and consequently, multiple births.

More recently, Keith and Keith (1999) reported that the incidence of multiple births, including twinning, is increasing in the industrialized nations of the world, particularly in the US, at a fast rate. This, they said, is likely due to the increasing numbers of mothers who delay pregnancy until later in life in order to pursue their careers. In addition, the widespread use of assisted reproductive technologies such as in vitro fertilization, which have improved tremendously over time, have also contributed to the increase in multiple births. Keith and Keith (1999) went further to highlight the risks and complications associated with multiple births among which are, low birth weight, high frequency of pre-term labour, higher mortality than single births and an increased risk of cerebral palsy which increases as birth weight falls.

The importance of population genetics in anthropological studies and public health management has never been in doubt. However, there are no current reliable basic data on the genetics of the Ghanaian population including twin-

Address for correspondence: Dr A. Mosuro, Department of Zoology, University of Ghana, Legon, Accra, Ghana. Email: <surrie19 @hotmail.com>

Manuscript received 7 February 200 I, accepted I March200 I. 
ning rates. This study therefore seeks to determine the incidence of twin births in Ghana.

\section{Materials and Method}

The data of the incidence of twin births for this study were obtained from the Korle-Bu Teaching Hospital in Accra and the Komfo Anokye Teaching Hospital in Kumasi, the two major teaching hospitals in the country. The data collected from these hospitals consisted of single and twin births recorded over a 12-year period in Accra (1988-1999) and a 15-year period in Kumasi (1985-1999). All data were collected from hospital records in the births registry in the Department of Obstetrics and Gynaecology in both teaching hospitals. The data comprised live single and multiple births as well as stillbirths. Both sets of twin birth data from both hospitals were analyzed by month and year but were not analyzed for type of twins delivered, that is, whether monozygotic (identical) or dizygotic (fraternal), owing to poor data recording. In addition, little information could be obtained about the age and parity of the mothers so, no analyses of these factors could be done. The lack of data on the type of twins delivered is not expected to affect the results obtained in the study. Nylander (1969) had reported that the occurrence of monozygotic twins in various populations worldwide is fairly constant and that the differences in twinning rates could be attributed to the occurrence of dizygotic twins.

The collected data were analyzed to determine the number of single births (x), the number of twin births (y) and the number of single births for every twin delivery $(\mathrm{x} / \mathrm{y})$. The number of twin births in every 1000 deliveries was computed as:

$\frac{\text { Twin maternities }(\mathrm{y})}{\text { Total number of maternities }(\mathrm{z})} \times 1000 \quad$ (Nylander, 1969)

The teaching hospitals were favoured for the survey for the fact that they took care of most of the births in Accra and Kumasi. Health care delivery is a priority with the government and is partly subsidized. These hospitals are government owned and funded and adequately staffed with highly trained personnel to cater for all medical eventualities including high-risk pregnancies such as multiple deliveries. The hospitals offer a high standard of reproductive care. Indeed, complicated cases from the private hospitals are often referred to the teaching hospitals. And with a dwindling economy, medical care, particularly maternity cases, is easily affordable in the teaching hospitals. A large proportion of the population can ill-afford the expenses of private hospitals.

\section{Results}

The annual incidence of twin births recorded in Accra between 1988 and 1999 is shown in Table 1. The highest rate of twin births per thousand deliveries recorded was 45 in 1999 and the lowest was 28.5 in 1993 . The total average number of twin births in every thousand deliveries for the 12-year study period was 33.4, indicating that for every 29 single births; there was a twin delivery.

The incidence of twin births in Kumasi was analyzed and is summarized in Table 2. The total average number of twin births per thousand deliveries for the 15-year sample period was 26.6. The highest incidence of 37.5 twin births per thousand births was recorded in 1996 while the lowest incidence of 20.4 was recorded in 1995 . Thus, in Kumasi, on the average, there was a twin delivery for every 36.6 single births.

\section{Discussion}

The incidence of twinning among the different races of the world has been extensively studied. Bulmer (1970) reported twinning rates to be lowest among Asian women with less than four twin births per thousand deliveries. The incidence has been reported to be highest among the Negroids and the highest values ever recorded were among the

\section{Table 1}

Summary of the Annual Incidence of Twin Births Recorded in the Korle-Bu Teaching Hospital, Accra, Ghana, Over a Period of 12 years (1988-1999)

\begin{tabular}{lccccc}
\hline Year & $\begin{array}{c}\text { Single Deliveries } \\
(\mathrm{X})\end{array}$ & $\begin{array}{c}\text { Twin Deliveries } \\
(\mathrm{Y})\end{array}$ & $\begin{array}{c}\text { Total Deliveries } \\
(\mathrm{Z})\end{array}$ & $\begin{array}{c}\text { Single Births } \\
\text { For Each Twin Delivery (X/Y) }\end{array}$ & $\begin{array}{c}\text { Twin Births Per } \\
1000 \text { Deliveries }\end{array}$ \\
\hline 1988 & 4396 & 145 & 4541 & 30.3 & 31.9 \\
1989 & 6265 & 220 & 6485 & 28.5 & 33.9 \\
1990 & 8202 & 261 & 8463 & 31.4 & 30.8 \\
1991 & 9585 & 319 & 9904 & 30 & 32.2 \\
1992 & 9167 & 309 & 9476 & 29.7 & 32.6 \\
1993 & 10979 & 322 & 11301 & 34.1 & 28.5 \\
1994 & 5388 & 211 & 5599 & 25.5 & 37.7 \\
1995 & 11098 & 402 & 11500 & 27.6 & 35 \\
1996 & 10887 & 325 & 11212 & 33.5 & 29 \\
1997 & 11672 & 378 & 12050 & 30.9 & 31.4 \\
1998 & 11082 & 384 & 11466 & 28.9 & 33.5 \\
1999 & 10530 & 496 & 11026 & 21.2 & 45 \\
TOTAL & 109251 & 3772 & 113023 & 29 & 33.4 \\
\hline
\end{tabular}


Table 2

Summary of the Annual Incidence of Twin Births Recorded in the Komfo Anokye Teaching Hospital, Kumasi, Ghana, Over a Period of 15 Years (1985-1999).

\begin{tabular}{|c|c|c|c|c|c|}
\hline Year & $\begin{array}{l}\text { Single Deliveries } \\
\text { (X) }\end{array}$ & $\begin{array}{l}\text { Twin Deliveries } \\
\text { (Y) }\end{array}$ & $\begin{array}{l}\text { Total Deliveries } \\
\text { (Z) }\end{array}$ & $\begin{array}{l}\text { Single Births } \\
\text { For Each Twin Delivery (X/Y) }\end{array}$ & $\begin{array}{l}\text { Twin Births Per } \\
1000 \text { Deliveries }\end{array}$ \\
\hline 1985 & 8217 & 172 & 8389 & 47.8 & 20.5 \\
\hline 1986 & 8600 & 204 & 8804 & 42.2 & 23.2 \\
\hline 1987 & 7847 & 216 & 8063 & 36.3 & 27.8 \\
\hline 1988 & 7749 & 175 & 7924 & 44.3 & 21.1 \\
\hline 1989 & 8346 & 236 & 8582 & 35.4 & 27.5 \\
\hline 1990 & 8133 & 184 & 8317 & 44.2 & 22.1 \\
\hline 1991 & 8127 & 209 & 8336 & 38.9 & 25.7 \\
\hline 1992 & 7794 & 179 & 7973 & 43.5 & 22.5 \\
\hline 1993 & 7499 & 211 & 7710 & 35.7 & 27.4 \\
\hline 1994 & 3682 & 99 & 3781 & 37.2 & 26.2 \\
\hline 1995 & 5869 & 143 & 6016 & 39.9 & 20.4 \\
\hline 1996 & 7004 & 273 & 7277 & 25.7 & 37.5 \\
\hline 1997 & 6473 & 210 & 6683 & 30.8 & 31.4 \\
\hline 1998 & 7401 & 272 & 7673 & 27.2 & 35.4 \\
\hline 1999 & 5507 & 167 & 5674 & 33 & 29.4 \\
\hline TOTAL & 108248 & 2954 & 111202 & 36.6 & 26.6 \\
\hline
\end{tabular}

Yoruba tribe of southwest Nigeria with approximately 50 twin births per thousand deliveries. This is more than four times that of any Caucasian population.

Among the earliest reports of the incidence of twinning in Nigeria is that of Bulmer (1960) who reported an incidence of 44.9 twin births per thousand births in Ibadan. Nylander (1979) in a survey carried out in Igbo-Ora and Ibadan between 1967 and 1969 obtained higher values of 48.3 and 57.2 twin births per thousand births, respectively. These rates were subsequently proclaimed the highest in the world. Mosuro (1996) reported an incidence of 68.1 twin births per thousand deliveries for Igbo-Ora, 37.2 for Ibadan and 26.9 for Lagos in a survey carried out between 1985 and 1989. His survey utilized a larger population sample and a longer time span than the earlier works. He concluded that the rates seen in the urban cities of Ibadan and Lagos were relatively lower than that of rural Igbo-Ora owing to the highly cosmopolitan, heterogeneous population found in the cities, which favoured the mixing of genes through interbreeding. Igbo-Ora, on the other hand, was still believed to be homogeneous culturally, socially, ethnically, and might have even been consanguineous. Such a close knit population which encouraged marriage between close relatives, was naturally expected to have a high twinning rate if it was so genetically predisposed. Furthermore, if social class does play a significant role in twinning, one then expects the twinning rates in Igbo-Ora, which is populated by rural people of the lowest social class, to be much higher than the rates observed in the urban cities, which have a relatively higher standard of living. Nylander (1981) in a study in Nigeria, had reported that the twinning rate in the lowest social class was over twice that in the middle and highest social classes.
No twin birth data exist for the Ghanaian population but it is plausible to assume that the twin birth rates will compare favourably with values obtained from other African populations and that similar factors would influence the twin birth rates. Indeed, most of sub-Saharan Africa is a culturally heterogeneous area whose demographic profiles have some identical and unique characteristics. For one, the fertility regimes of the area remain among the highest in the world (Van de Walle, 1987).

The labour demands of a subsistence economy using primitive manual technology coupled with the high mortality in Africa, have made it imperative to insure against the possible death of children by multiplying their numbers. Gaisie (1964) in his study of some of the demographic parameters in Ghana, reported that prolific childbearing was encouraged in the traditionally oriented Ghanaian society where the social and political institutions made it not only possible, but also desirable and praiseworthy for a woman to bear children all through her reproductive years. Kpedekpo (1968) stated that Ghanaians generally viewed having many children as economic assets, prestigious and an insurance against high infant mortality. He said further that the Ghanaian woman on the average produces 4-5 children during her reproductive years making her one of the most fertile in the world. Addo and Goody (1975) estimated the total fertility rate to be between 6.2 and 7.1 , ranging from 4.95 per woman in Accra to 6.61 per woman in Ashanti whose heartland is Kumasi. It is plausible to suggest that the high twin birth rates seen in this study could have been as a consequence of these high fertility rates and parity.

Hormonal stimulation using fertility drugs and the various techniques utilized in assisted reproductive technol- 
ogy have been reported to be indicative of high multiple birth rates. No evidence exists as to what proportion of twin births in this study were due to fertility drugs. Indeed, Africa is the largest remaining part of the world where the use of fertility drugs to determine family size, has made little or no impact. Assisted reproductive technology, particularly in vitro fertilization, though desirable, comes at such a prohibitive cost and only very few women in the higher socioeconomic stratum can afford it. In Ghana, such services are not available as yet. However, in sub-Saharan Africa, efforts are rather being directed at family limitation with the use of contraceptive techniques to limit family size. Here again, very little has been achieved (Van de Walle, 1987).

Typically, demographic studies in Ghana have tended to cover Accra and Kumasi, the two largest cities in the country with the highest population densities and results from such studies have been adopted as being fairly representative of the entire country. Accra is the capital and commercial centre and is cosmopolitan in outlook and also populated by peoples from all over the country. Kumasi on the other hand is the major city of the Ashanti, the largest ethnic group in Ghana.

If we consider the findings of Keith and Keith (1999) that the number of multiple births is on the increase in the industrialized countries, we could soon experience a similar increase in these African populations studied as they slowly attempt to adopt western cultural values, placing a higher premium on career to the detriment of family values. Accordingly, the number of women who will delay pregnancy until later in life will increase with the probable consequence of increasing twinning rates.

\section{References}

Addo, N.O., \& Goody, J.R. (1975). Siblings in Ghana. Accra, Ghana: Population Dynamics Programme Publishers.

Bulmer, M.G. (1960). The twinning rate in Europe and Africa. Annals of Human Genetics, 24, 121-125.
Bulmer, M.G. (1970). The Biology of Twinning in Man. Oxford: Clarendon Press

Campbell, D.M., Campbell, A.J., \& MacGillivray, A. (1974). Material characteristics of women having twin pregnancies. I. Biosocial Science, 6, 463.

Edgley, R. (1969). Binovular twins in a patient taking oral contraceptives. Medical Journal of Australia, 2, 1233.

Fellman, J., \& Eriksson, A.W. (1999). Statistical analysis of the seasonal variation in the twinning rate. Twin Research, 2, 22-29.

Gaisie, S.K. (1964). An analysis of fertility levels and differentials in contemporary Ghana. Masters Thesis, University of London.

Goswami, H.K. (1970). Studies on twins. Acta Geneticae Medicae et Gemellologiae, 19, 43.

Keith, L., \& Keith, D. (1999). Multiple Birth: Epidemiology, perinatal outcomes and long term sequelae. Chicago: Centre for Study of Multiple Birth. Article \#1.

Kpedekpo, G.M.K. (1968). The Eastern region demographic survey. Institute of Statistical, Social and Economic Research Technical publication series, No. 5. Legon, Accra: ISSER, University of Ghana.

MacGillivray, I. (1981). The probable explanation for the falling twinning rate in Scotland. Twin Research 3: Twin Biology and Multiple Pregnancy, 57-69.

Mosuro, A.A. (1996). Twinning rates in southwest Nigeria. Nigerian Journal of Science, 30, 39-45.

Nylander, P.P.S. (1969). The value of the placenta in the determination of zygosity. A study of 1052 Nigerian twin maternities. Journal of Obstetrics and Gynaecology of the British Commonwealth, 76, 699.

Nylander, P.P.S. (1979). The twinning incidence in Nigeria. Acta Geneticae Medicae et Gemellologiae, 28, 261-263.

Nylander, P.P.S. (1981). The factors that influence twinning rates. Acta Geneticae Medicae et Gemellologiae, 30, 189-202.

Van de Walle, E. (1987). The cultural roots of fertility regimes. Philadelphia: University of Pennsylvania Press. 